\title{
UBC-Nepal Expedition
}

\section{Haemoconcentration underlies the reductions in cerebral blood flow observed during acclimatization to high altitude}

Howe, Connor A; Ainslie, Philip N; Tremblay, Joshua C; Carter, Howard Henry; Patrician, Alex; Stembridge, Mike; Williams, Alex; Drane, Aimee L; Delorme, Eric; Rieger, Mathew G; Tymko, Michael M; Gasho, Chris; Santoro, Antoinette; MacLeod, David B; Hoiland, Ryan L

\section{Published in:}

Experimental Physiology

DOI:

10.1113/EP087663

Publication date:

2019

Document version

Peer reviewed version

Citation for published version (APA):

Howe, C. A., Ainslie, P. N., Tremblay, J. C., Carter, H. H., Patrician, A., Stembridge, M., Williams, A., Drane, A. L., Delorme, E., Rieger, M. G., Tymko, M. M., Gasho, C., Santoro, A., MacLeod, D. B., \& Hoiland, R. L. (2019). UBC-Nepal Expedition: Haemoconcentration underlies the reductions in cerebral blood flow observed during acclimatization to high altitude. Experimental Physiology, 104(12), 1963-1972. https://doi.org/10.1113/EP087663 


\section{Experimental Physiology}

https://ep.msubmit.net

\section{EP-RP-2019-087663R1}

Title: UBC-Nepal Expedition: Haemoconcentration underlies the reductions in cerebral blood flow observed during acclimatization to high-altitude

Authors: Connor A Howe

$$
\begin{aligned}
& \text { Philip N Ainslie } \\
& \text { Joshua C Tremblay } \\
& \text { Howard H Carter } \\
& \text { Alex Patrician } \\
& \text { Mike Stembridge } \\
& \text { Alexandra M Williams } \\
& \text { Aimee Drane } \\
& \text { Eric Delorme } \\
& \text { Mathew G Rieger } \\
& \text { Michael M Tymko } \\
& \text { Chris Gasho } \\
& \text { Antoinette Santoro } \\
& \text { David B MacLeod } \\
& \text { Ryan L Hoiland }
\end{aligned}
$$

Author Conflict: No competing interests declared

Running Title: Impact of haemoconcentration on cerebral blood flow at high-altitude

Abstract: At high-altitude, increases in haematocrit (Hct) are achieved through altitude- 
induced diuresis and erythropoiesis, both of which result in increased arterial oxygen content (CaO2). Given the impact alterations in $\mathrm{Hct}$ have on $\mathrm{CaO} 2$, haemoconcentration

has been hypothesized to partly mediate the attenuation of the initial elevation in cerebral blood flow (CBF) at high-altitude. To test this hypothesis, healthy males $(n=13)$ ascended to $5050 \mathrm{~m}$ over nine days without the aid of prophylactic acclimatization

medications. Following one-week of acclimatization at $5050 \mathrm{~m}$, participants were haemodiluted by rapid saline infusion ( 2.10 \{plus minus\} $0.28 \mathrm{~L}$ ) to return Hct towards pre-acclimatized levels. Arterial blood gases, Hct, global CBF (duplex ultrasound), and haemodynamic variables were measured following initial arrival to $5050 \mathrm{~m}$, and after one-week of acclimatization at high-altitude, prior to and following the haemodilution protocol. Following one-week at $5050 \mathrm{~m}$, Hct increased from 42.5 \{plus minus\}2.5 to

$49.6\{$ plus minus\} $2.5 \%(\mathrm{P}<0.001)$, and was subsequently reduced to $45.6\{$ plus minus\}2.3 \% $(\mathrm{P}<0.001)$ following haemodilution. Global CBF decreased from 844 \{plus

minus 3160 to 619 \{plus minus $\} 136 \mathrm{~mL} / \mathrm{min}(\mathrm{P}=0.033)$ following one-week of

acclimatization and increased to 714 \{plus minus\}204 mL/min $(P=0.045)$ following haemodilution. Despite the significant changes in $\mathrm{Hct}$, and thus $\mathrm{CaO} 2$, cerebral oxygen delivery was unchanged at all time points. Furthermore, these observations occurred in the absence of any changes in mean arterial blood pressure, cardiac output, arterial blood $\mathrm{pH}$, or oxygen saturation pre- and post-haemodilution. These data highlight the influence of Hct in the regulation of CBF and are the first to demonstrate experimentally that haemoconcentration contributes to the reduction in $\mathrm{CBF}$ during acclimatization to altitude.

New Findings: 1 . What is the central question of this study? To evaluate the degree to which increases in haematocrit alters cerebral blood flow and cerebral oxygen delivery during acclimatization to high-altitude 2 . What is the main finding and its importance? Through haemodilution, we determined that, following one week of acclimatization, the primary mechanism contributing to the cerebral blood flow acclimatization response is

generated by increases in haemoglobin and haematocrit, while the remaining contribution to the cerebral blood flow acclimatization response is likely attributable to ventilatory acclimatization

\section{Dual Publication: No}

Funding: Canada Research Chairs (Chaires de recherche du Canada): Philip N Ainslie, F11-02423 
1 Title: UBC-Nepal Expedition: Haemoconcentration underlies the reductions in

2 cerebral blood flow observed during acclimatization to high-altitude

3

4

5

6

7

8

9

10

11

12

13

14

15

16

17

18

19

20 Affiliations:

$21{ }^{I}$ Centre for Heart, Lung and Vascular Health, University of British Columbia - Okanagan

22 Campus, School of Health and Exercise Sciences, 3333 University Way, Kelowna, B.C., Canada, $23 \quad$ VIV $1 V 7$
Connor A. Howe ${ }^{1}$

Philip N. Ainslie ${ }^{1}$

Joshua C. Tremblay ${ }^{3}$

Howard H. Carter ${ }^{4}$

Alex Patrician ${ }^{1}$

Mike Stembridge ${ }^{5}$

Alex Williams ${ }^{6}$

Aimee L. Drane ${ }^{5}$

Eric Delorme ${ }^{1}$

Mathew G. Rieger ${ }^{1}$

Michael M. Tymko ${ }^{1}$

Chris Gasho ${ }^{7}$

Antoinette Santoro ${ }^{2}$

David B. MacLeod ${ }^{2}$

Ryan L. Hoiland ${ }^{1}$ 
$24{ }^{2}$ Department of Anesthesiology, Duke University Medical Center, Durham, NC, 27708, USA

$25{ }^{3}$ Cardiovascular Stress Response Laboratory, School of Kinesiology and Health Studies, Queen's 26 University, 28 Division Street, Kingston, O.N., Canada, K7L 3N6

$27{ }^{4}$ Department of Nutrition, Exercise and Sports, University of Copenhagen, Nфrre Allé 51, DK282200 Copenhagen, Denmark

$29{ }^{5}$ Cardiff Centre for Exercise and Health, Cardiff Metropolitan University, Cyncoed Road, 30 Cardiff, CF23 6XD Wales, $U K$

$31{ }^{6}$ International Collaboration on Repair Discoveries, University of British Columbia, Vancouver, 32 British Columbia, Canada.

$33{ }^{7}$ VA Loma Linda Healthcare System and Loma Linda University School of Medicine, Loma 34 Linda, CA, USA

35

36

37 Corresponding Author:

38 C.A. Howe: Centre for Heart, Lung and Vascular Health, School of Health and Exercise 39 Sciences, University of British Columbia - Okanagan, 3333 University Way, Kelowna, British 40 Columbia, Canada, V1V 1V7. Email: connorahowe@gmail.com 


\section{$41 \quad$ New Findings}

42 The central question of this study was to evaluate the degree to which increases in haematocrit

43 alter cerebral blood flow and cerebral oxygen delivery during acclimatization to high-altitude.

44 Through haemodilution, we determined that, following one-week of acclimatization, the primary

45 mechanism contributing to the cerebral blood flow response during acclimatization is increases in

46 haemoglobin and haematocrit, while the remaining contribution to the cerebral blood flow

47 response during acclimatization is likely attributable to ventilatory acclimatization.

49 ABSTRACT

50 At high-altitude, increases in haematocrit (Hct) are achieved through altitude-induced diuresis

51 and erythropoiesis, both of which result in increased arterial oxygen content $\left(\mathrm{CaO}_{2}\right)$. Given the

52 impact alterations in Hct have on $\mathrm{CaO}_{2}$, haemoconcentration has been hypothesized to partly

53 mediate the attenuation of the initial elevation in cerebral blood flow (CBF) at high-altitude. To

54 test this hypothesis, healthy males $(n=13)$ ascended to $5050 \mathrm{~m}$ over nine days without the aid of

55 prophylactic acclimatization medications. Following one-week of acclimatization at $5050 \mathrm{~m}$,

56 participants were haemodiluted by rapid saline infusion $(2.10 \pm 0.28 \mathrm{~L})$ to return Hct towards pre-

57 acclimatized levels. Arterial blood gases, Hct, global CBF (duplex ultrasound), and

58 haemodynamic variables were measured following initial arrival to $5050 \mathrm{~m}$, and after one-week

59 of acclimatization at high-altitude, prior to and following the haemodilution protocol. Following

60 one-week at 5050m, Hct increased from $42.5 \pm 2.5$ to $49.6 \pm 2.5 \% \quad(\mathrm{P}<0.001)$, and was

61 subsequently reduced to $45.6 \pm 2.3 \%(\mathrm{P}<0.001)$ following haemodilution. Global CBF decreased

62 from $844 \pm 160$ to $619 \pm 136 \mathrm{~mL} / \mathrm{min}(\mathrm{P}=0.033)$ following one-week of acclimatization and 
63 increased to $714 \pm 204 \mathrm{~mL} / \mathrm{min}(\mathrm{P}=0.045)$ following haemodilution. Despite the significant

64 changes in Hct, and thus $\mathrm{CaO}_{2}$, cerebral oxygen delivery was unchanged at all time points.

65 Furthermore, these observations occurred in the absence of any changes in mean arterial blood

66 pressure, cardiac output, arterial blood $\mathrm{pH}$, or oxygen saturation pre- and post-haemodilution.

67 These data highlight the influence of Hct in the regulation of CBF and are the first to demonstrate 68 experimentally that haemoconcentration contributes to the reduction in $\mathrm{CBF}$ during 69 acclimatization to altitude.

\section{INTRODUCTION}

A reduction in the partial pressure of atmospheric oxygen results in hypoxemia, whereby

73 necessary cerebrovascular responses are required to maintain adequate cerebral oxygen delivery

$74\left(\mathrm{CDO}_{2}\right)$. Upon ascent to high-altitude, cerebral blood flow (CBF) increases in proportion to the

75 degree of hypoxemia to compensate for the reduced arterial oxygen content $\left(\mathrm{CaO}_{2}\right)($ Severinghaus

76 et al., 1966; Ainslie \& Subudhi, 2014). Within two- to three-days following initial arrival to high-

77 altitude, $\mathrm{CBF}$ begins to decrease, returning to sea-level values typically between 7-14 days at a

78 given altitude (Willie et al., 2014), yet no mechanism(s) have been clearly ascribed to this pattern

79 of $\mathrm{CBF}$ changes. It is well established that hypoxic $\mathrm{CBF}$ regulation is driven by changes in $\mathrm{CaO}_{2}$

80 to maintain consistent $\mathrm{CDO}_{2}$ during arterial hypoxemia at sea-level [reviewed in: (Hoiland et al.,

81 2016)]. This regulation of blood flow is similar to that of the systemic circulation during exercise

82 (Roach et al., 1999; Gonzalez-Alonso et al., 2001), whereby flow is coupled to $\mathrm{CaO}_{2}$, but not the 83 partial pressure of arterial oxygen $\left(\mathrm{PaO}_{2}\right)$. Thus, the pattern of CBF changes observed at high84 altitude are also likely regulated by changes in $\mathrm{CaO}_{2}$ (Ainslie \& Subudhi, 2014; Hoiland et al., 
85 2018). The primary factors influencing $\mathrm{CaO}_{2}$ at high-altitude, and by association $\mathrm{CBF}$, are 86 changes in arterial oxygen saturation $\left(\mathrm{SaO}_{2}\right)$, hematocrit $(\mathrm{Hct})$. This is in addition to the well 87 documented influence of the partial pressure of carbon dioxide $\left(\mathrm{PaCO}_{2}\right)$ and $\mathrm{pH}$ on $\mathrm{CBF}$. 88 Alterations in cerebrovascular reactivity to $\mathrm{CaO}_{2}$ and/or $\mathrm{PaCO}_{2}$ may also underlie changes in $\mathrm{CBF}$

at altitude (Lucas et al., 2011; Willie et al., 2015) although their contribution to CBF changes during acclimatization is likely modest at best [reviewed in: (Hoiland et al., 2018)].

Early increases in Hct occur through high-altitude induced diuresis whereby elevated arterial $\mathrm{pH}$ stimulates bicarbonate to be excreted by the kidneys through the urine, reducing plasma volume. This response partially mitigates the initial reductions in $\mathrm{CaO}_{2}$ (Pugh, 1964; Ryan et al., 2014; Siebenmann et al., 2017). Thereafter, following approximately one-week at altitude, Hct increases further through erythropoiesis (Siebenmann et al., 2017). While $\mathrm{PaO}_{2}$ and $\mathrm{SaO}_{2}$ increase and $\mathrm{PaCO}_{2}$ decreases as a result of ventilatory acclimatization [reviewed in: (Hoiland et al., 2018], previous research has speculated that increased Hct provides a greater input into the changes in $\mathrm{CaO}_{2}$ observed at altitude. Indeed, estimations indicate Hct may account for 60-70\% of the increase in $\mathrm{CaO}_{2}$ during acclimatization, and therefore possess a commensurate influence on the reduction in $\mathrm{CBF}$ observed across acclimatization (Hoiland et al., 2018). Importantly, $\mathrm{CaO}_{2}$ regulates hypoxic vasodilation via changes in $\mathrm{PaO}_{2} / \mathrm{SaO}_{2}$ as well as independent of alterations in $\mathrm{PaO}_{2} / \mathrm{SaO}_{2}$ such as when Hct is altered [reviewed in: (Hoiland et al., 2016)]. However, this regulation of CBF by Hct appears unrelated to changes in blood viscosity [(Brown \& Marshall, 1985; reviewed in: Hoiland et al 2016)]. This understanding of the fundamental importance of $\mathrm{CaO}_{2}$ in the regulation of hypoxic cerebral vasodilation has been long standing (Brown et al., 1985); however, the influence of Hct on CBF during acclimatization at altitude due to its relationship with $\mathrm{CaO}_{2}$ has never been experimentally determined. 
The aim of this study was to evaluate the degree to which Hct alters $\mathrm{CBF}$ and $\mathrm{CDO}_{2}$ by acutely haemodiluting subjects to pre-acclimatized Hct concentrations observed upon initial 110 arrival to $5050 \mathrm{~m}$. We hypothesized that following approximately seven days of acclimatization at $1115050 \mathrm{~m}$ above sea-level, CBF would be significantly decreased from initial arrival values 112 concomitant with an increase in Hct. Further, we hypothesized that following haemodilution, due 113 to the experimentally isolated reduction in Hct, $\mathrm{CBF}$ would concomitantly increase and thus be 114 partially restored to near pre-acclimatized levels.

116 METHODS

118 Ethical approval

All participants gave written informed consent prior to participating. This study was approved by the University of British Columbia Clinical Research Ethics Board, the Nepal Health

121 Research Council, and conformed to the standards set by the Declaration of Helsinki (except 122 registry in a database) and the Canadian Government Tri-council Policy Statement (TCPS2) for 123 integrity in research.

125 Participants

126 Thirteen healthy male participants (BMI: $23.2 \pm 2.1 \mathrm{~kg} \cdot \mathrm{m}^{-2}$, Age: $27 \pm 5$ years) were 127 recruited to participate in this study. Participants were recruited at the University of British 128 Columbia's Okanagan campus and were part of the research team. This project was part of a 129 larger expedition to the EV-K2-CNR Italian Pyramid Research laboratory in the Khumbu Valley, 
130 Nepal at $5050 \mathrm{~m}$ that took place September to November 2016 (Willie et al., 2018). Although 131 participants were recruited to other projects at the Pyramid Laboratory, all arrived to high-altitude 132 at the same time and were tested $>5$ half-lives following any drug interventions. Further, all 133 participants abstained from exercise, caffeine, and alcohol for 24 hours prior to testing and 134 arrived having fasted for $>4$ hours. All participants were born and lived at or near sea-level and 135 were free of cardiovascular, respiratory and neurological diseases and were non-smokers. One 136 participant was taking Pentasa ${ }^{\circledR}$, a medication used to treat inflammatory bowel disease, 137 throughout the entire study.

\section{Experimental Overview}

The research team travelled to Nepal to begin the ascent to high-altitude. All participants 141 spent 3-9 days in Kathmandu (1400 m) prior to flying to Lukla (2860 m) to begin the trek to the

142 EV-K2-CNR Pyramid Research Laboratory $(5050 \mathrm{~m})$. Ascent to the Pyramid Laboratory took 143 place over a slow and safe 9-day trek without the use of any acute mountain sickness 144 prophylactics

145 (e.g., acetazolamide). Participants spent one night in Monjo (2800 m), three nights in Namche 146 Bazaar (3400 m), one night in Deboche $(3820 \mathrm{~m})$, and then three nights in Pheriche (4371 m) 147 followed by the final trekking day to the Pyramid Laboratory $(5050 \mathrm{~m})$. Due to the length of 148 testing per participant, and hours available for testing at the remote laboratory, testing was limited 149 to two participants per day. As such, participants underwent the haemodilution protocol across a 150 small range of relative acclimatization with testing conducted on days 4-10 (avg. 7) at the 151 Pyramid Laboratory (Figure 1). For more details on the ascent see (Willie et al., 2018). 
The day following initial arrival to the pyramid lab (i.e. day 1), subjects lay supine for 20

153 minutes of quiet rest, after which $\mathrm{CBF}$, echocardiography and arterial blood samples were

154 acquired. A minimum of 24 hours prior to the main experimental protocol participants' blood 155 volumes were measured using the Carbon Monoxide Rebreathe technique (Schmidt \& Prommer, 156 2005). This protocol is detailed in the following section (Experimental Measures). The following 157 day, participants completed the experimental protocol prior to and following haemodilution. After 15820 minutes of quiet supine rest participants were cannulated, following which, CBF, cardiac 159 output (Q), and radial arterial blood measures were acquired. A hypervolemic haemodilution 160 protocol was performed in an attempt to return Hct and plasma volume to pre-acclimatized values 161 observed upon initial arrival at high-altitude (i.e., Hct $\approx 45 \%)$ through rapid saline infusion $(0.9$ $162 \% \mathrm{NaCl}$ ). Prior to expedition testing, pilot work was conducted to determine the adequate 163 infusion volume of saline required to elicit the desired decrease in Hct. A bolus infusion of saline 164 equal to between $30-35 \%$ of the participants total blood volume (avg 2.10 $\pm 0.28 \mathrm{~L}$ ) was infused 165 over $0.5-1 \mathrm{hr}$.

166

167 Experimental Measures

168 A radial artery catheter (20-gauge; Arrow, Markham, ON, Canada) was inserted into the 169 left radial artery under local anesthesia (Lidocaine, 1.0\%) and ultrasound guidance using sterile 170 technique. The arterial catheter was attached to an inline waste-less sampling system (Edwards 171 Lifesciences, VAMP, CA, USA) and a pressure transducer that was placed at the height of the 172 right atrium (TruWave transducer). Following cannulation, subjects rested quietly for 20-minutes, 173 after which an arterial blood sample was taken, and analyzed (ABL90 FLEX, Radiometer, 174 Copenhagen, Denmark). 
Internal carotid artery (ICA) and vertebral artery (VA) image acquisition was obtained using a $10 \mathrm{MHz}$ multi-frequency linear array probe attached to a high-resolution ultrasound 177 machine (15L4, Terason t3200, Burlington, MA, USA). Arterial diameter was measured with B178 mode imaging while pulse-wave mode simultaneously measured blood velocity within the vessel.

179 Image location was selected on an individual basis in order to ensure clear, highly reproducible 180 measures with VA imaging occurring between cervical vertebrate 4 and 5, 5 and 6 or proximal to 181 entry into the vertebral column and ICA imaging taken $\geq 1.5 \mathrm{~cm}$ distal to the common carotid 182 bifurcation. The sum of both ICA and VA flow multiplied by two was used to estimate global 183 cerebral blood flow (gCBF). Cerebrovascular reactivity to $\mathrm{CaO}_{2}$ was also assessed using the 184 concurrent ultrasound blood flow values and arterial blood samples. $\mathrm{CaO}_{2}$ was calculated from 185 the arterial blood sample utilizing the arterial $\mathrm{SpO}_{2}, \mathrm{PaO}_{2}$, and $[\mathrm{Hb}]\left(\mathrm{CaO}_{2}=\left(1.34 \times[\mathrm{Hb}] \times \mathrm{SaO}_{2}\right)\right.$ $186+\left(0.003 \times \mathrm{PaO}_{2}\right)$.

187 Upon initial arrival (day 1), blood pressure was assessed using an automated blood 188 pressure cuff (HEM775CAN, Omron Healthcare). During the haemodilution protocol, blood 189 pressure was assessed continuously by means of intra-radial pressure through the radial arterial 190 catheter and was corrected to manual brachial blood pressure measurements (i.e. auscultation). A 191 portable ultrasound (Vivid Q, GE Healthcare, Piscataway, NJ, USA) was used for the 192 echocardiography assessment of cardiac output (Q). Participants were rolled into the left lateral 193 decubitus position whereby a trained cardiac sonographer acquired parasternal and apical images. 194 Stroke volume (SV) was calculated from the diameter of the left ventricular outflow tract 195 diameter and the velocity-time integral from a five-chamber view (Lang et al., 2015). Reliability 196 values for a range of echocardiographic variables from our group have previously been reported 
197 (Stembridge et al., 2014). Heart rate was obtained from the R-R intervals recorded from a three 198 lead ECG and multiplied by SV to calculate Q.

Assessment of total blood volume

Total blood volume was determined using the previously validated carbon monoxide 202 rebreathing method, as described in detail elsewhere (Schmidt \& Prommer, 2005). Using a 203 custom glass spirometer (Blood Tec) and a 5-liter reservoir bag of $100 \% \mathrm{O}_{2}$, participants were 204 instructed to maximally inhale a specific volume of carbon monoxide $\left(0.8 \mathrm{~mL} \cdot \mathrm{kg}^{-1}\right)$ which was 205 inserted into the apparatus mid inspiration. Participants then held their breath at maximal 206 inspiration for 10 seconds before rebreathing on the apparatus for two-minutes. A venous blood 207 sample was obtained at baseline and seven minutes following onset of the carbon monoxide 208 rebreathing to determine total haemoglobin [Hb] and carboxyhaemoglobin (ABL 90; 209 Radiometer). Expired carbon monoxide was measured using a portable carbon monoxide analyzer 210 (Dräger Pac 3500; Draeger Safety) at baseline and at four- and seven-minutes post rebreathe 211 onset. Total red cell volume assessed by this measure was used to accurately calculate total blood 212 volume pre- and post- haemodilution in conjunction with Hct \%. Blood volume post 213 haemodilution was calculated using the initial blood volume, and Hct \% recorded from arterial 214 blood samples pre- and post- haemodilution (i.e. Hct Initial $\mathrm{x}$ blood volume Initial $=$ Hct $_{\text {Final }} \times$ blood 215 volume $\left._{\text {Final }}\right)$. 
217

218

219

220

221

222

223

224

225

226

227

228

229

230

231

232 in ICA and VA flow and reactivity were compared using a t-test following acclimatization and

233 haemodilution to examine regional $\mathrm{CBF}$ differences. Finally, linear regression analysis was

234 performed between both $\triangle \mathrm{gCBF}$ and $\mathrm{gCBF}$ reactivity versus days spent at altitude to delineate the 235 effect of testing day. Significance was set at $\mathrm{P}<0.05$ for all statistical analyses. 


\section{RESULTS}

238

239

240

241

242 remained slightly elevated following haemodilution. Both $\mathrm{PaO}_{2}$ and $\mathrm{SaO}_{2}$ increased following

243 acclimatization $\left(\mathrm{SaO}_{2}, \quad \mathrm{P}<0.01 ; \quad \mathrm{PaO}_{2}, \quad \mathrm{P}<0.001\right)$ and remained unchanged following

244 haemodilution $\left(\mathrm{SaO}_{2}, \mathrm{P}=0.78 ; \mathrm{PaO}_{2}, \mathrm{P}=0.79\right)$. Though $\mathrm{PaCO}_{2}$ significantly decreased following

245 acclimatization and following the haemodilution protocol, $\mathrm{pH}$ was only altered (increased)

246 following acclimatization, but remaining unchanged with haemodilution $(\mathrm{P}=0.39)$.
248

249

250

251

252 rate did not decrease following acclimatization $(\mathrm{P}=0.29)$, but was reduced following

253 haemodilution compared to initial arrival $(\mathrm{P}=0.03)$. Notably, heart rate did not change pre- to

254 post-haemodilution $(\mathrm{P}=0.15)$. Stroke volume decreased following acclimatization $(\mathrm{P}<0.01)$ and 255 then increased following hemodilution $(\mathrm{P}=0.02)$. Following haemodilution, $\mathrm{SV}$ was not 256 statistically different compared to initial arrival $(\mathrm{P}=0.051)$. These changes ultimately led to a 257 reduction in $\mathrm{Q}$ following acclimatization $(\mathrm{P}<0.01)$, whereby $\mathrm{Q}$ remained below initial arrival 
258 values following haemodilution $(\mathrm{P}=0.01)$. However, $\mathrm{Q}$ was not altered following haemodilution $259(\mathrm{P}=0.62)$.

260

261 CBF Results

262 Cerebrovascular results are presented in Figure 2. Following approximately one-week at $2635050 \mathrm{~m} \mathrm{gCBF}$ decreased by $20.9 \pm 23.6 \%$ from $843.8 \pm 160.2$ to $619.6 \pm 135.9 \mathrm{~mL} \cdot \mathrm{min}^{-1}$ $264(\mathrm{P}<0.001)$. This decrease was mediated by reductions in blood flow through both the ICA and VA $265 \quad(-14.2 \pm 23.2 \% ; \mathrm{P}<0.01$ and $-22.3 \pm 33.2 \% ; \mathrm{P}<0.01$, respectively) (Figure 2). Following the 266 haemodilution trial, gCBF was elevated by $15.3 \pm 18.8 \%$ to $714.1 \pm 203.5 \mathrm{~mL} \cdot \mathrm{min}^{-1}(\mathrm{P}=0.045)$ 267 due to an increase in ICA blood flow $(+15.7 \pm 19.7 \%$; $\mathrm{P}=0.03)$ while blood flow in the VA only 268 increased marginally and non-significantly $(+15.5 \pm 28.4 \% ; \mathrm{P}=0.305)$. Post haemodilution, gCBF 269 remained significantly lower compared to initial arrival at high-altitude $(\mathrm{P}=0.033)$. At each time 270 point, $\mathrm{gCBF}$ was regulated to the extent that $\mathrm{CDO}_{2}$ was unaltered across acclimatization $(126.2 \pm$ 27125.5 vs. $\left.114.4 \pm 22.7 \mathrm{~mL} \cdot \mathrm{min}^{-1}\right)$ and hemodilution $\left(121.6 \pm 30.2 \mathrm{~mL} \cdot \mathrm{min}^{-1}\right.$; main effect: $272 \mathrm{P}=0.302$ ). No regional differences were observed between the relative changes in ICA and VA 273 flow following acclimatization $(-14.20 \pm 23.15$ vs $-22.34 \pm 33.16 \% ; \mathrm{P}=0.10)$ or following 274 haemodilution $(15.72 \pm 19.67$ vs $15.52 \pm 28.36 \%$; $=0.98)$. Linear regression analysis indicated 275 there was no relationship between $\triangle \mathrm{gCBF}$ and day of testing $\left(\mathrm{R}^{2}=0.191 ; \mathrm{P}=0.135\right)$.

276

277

Blood volume

278 Blood volume data prior to and following haemodilution are presented in Table 3. Pre 279 haemodilution, individual blood volumes ranged from 5.47 to $7.75 \mathrm{~L}$ with a mean of $6.18 \pm 0.83$ 
280 L. Of this, red cell volume accounted for $3.07 \pm 0.49 \mathrm{~L}$ while plasma volume accounted for 3.11

$281 \pm 0.40 \mathrm{~L}$. Assuming blood volume and hematocrit were relatively unchanged within 24 hrs

282 following the carbon monoxide rebreathe assessment, blood volume post haemodilution was

283 calculated based on the pre-haemodilution blood data. From these calculations, the mean increase

284 in plasma volume and thus total blood volume observed following saline infusion was $0.54 \pm 0.14$

285 L. Notably, hydration status, as assessed by arterial blood osmolarity was not different pre- to 286 post-haemodilution $\left(288.14 \pm 2.21 \mathrm{vs} 289.00 \mathrm{vs} 2.11 \mathrm{mmol} \cdot \mathrm{Kg}^{-1}\right)$ and falls within euhydration 287 ranges (Armstrong et al., 2010).

\section{Mathematical estimation of CBF with a fully normalized Hct}

Despite the large saline infusion utilized $(2.10 \pm 0.28 \mathrm{~L})$, the haemodilution protocol

291 failed to fully revert Hct to initial arrival values (Table 1) and estimations based on total Hb mass

292 and Hct concentration indicate on average $540 \mathrm{~mL}$ of saline remained within the vasculature at

293 the time of measurement. Thus, an estimation of the CBF that would occur at a fully reversed

294 haemoconcentration was utilized. The group mean regression for $\Delta \mathrm{gCBF}\left(\mathrm{mL} \cdot \mathrm{min}^{-1}\right)$ per $\Delta \mathrm{Hct}$ 295 (\%) was $22.4 \mathrm{~mL} \cdot \mathrm{min}^{-1} \cdot \mathrm{Hct}^{-1}$ with individual values ranging from -17.96 to $82.33 \mathrm{~mL} \cdot \mathrm{min}^{-1}$.

$296 \mathrm{Hct}^{-1}$. Utilizing these reactivity slopes on an individual subject basis, we calculated that CBF 297 would have increased to $790.5 \mathrm{~mL} \cdot \mathrm{min}^{-1}$ had Hct been reduced by an additional $3.1 \%$ and fully 298 restored to the initial arrival value of $\sim 42.5 \%$. Cumulatively, addition of this theoretical change 299 in Hct leads to an overall $165.46 \mathrm{ml} \cdot \mathrm{min}^{-1}$ increase in $\mathrm{gCBF}$ from pre- to post-hemodilution. 300 This is inclusive of the experimentally elicited increase and additional estimated change (Figure 301 2). While accounting for the change in CBF with full normalization of Hct statistically eliminates 
302 the difference between initial arrival gCBF and that of the theoretical post-hemo gCBF $(843.8 \pm$ 303160.2 vs. $\left.790.5 \pm 266.8 \mathrm{~mL} \cdot \mathrm{min}^{-1} ; \mathrm{P}=0.62\right)$, this increase in $\mathrm{gCBF}$ is not sufficient to explain the 304 entire CBF response during acclimatization, which was a $224.13 \mathrm{ml} \cdot \mathrm{min}^{-1}$ decrease. Indeed, 305 these changes in gCBF are significantly different $\left(224.1 \pm 189.2 \mathrm{vs} .165 .5 \pm 212.1 \mathrm{~mL} \cdot \mathrm{min}^{-1}\right.$; $306 \mathrm{P}=0.02)$.

CBF reactivity to $\mathrm{CaO}_{2}$

Reactivity values from the linear mixed effects modelling are reported as mean \pm SD

(Figure 3). Following one-week of acclimatization and haemodilution gCBF reactivity was

311 unchanged $\left(-58.7 \pm 51.2 \mathrm{vs}-64.5 \pm 56.2\left[\Delta\left(\mathrm{mL} \cdot \mathrm{min}^{-1} \cdot \mathrm{mL}^{-1} \cdot \mathrm{dL}^{-1}\right)\right] \mathrm{P}=0.72\right)$. Additionally there 312 was no change in ICA reactivity to $\mathrm{CaO}_{2}\left(-18.1 \pm 18.7 \mathrm{vs}-22.9 \pm 20.2\left[\Delta\left(\mathrm{mL} \cdot \mathrm{min}^{-1} \cdot \mathrm{mL}^{-1} \cdot \mathrm{dL}^{-}\right.\right.\right.$

$\left.\left.\left.312^{1}\right)\right] ; \mathrm{P}=0.43\right)$ or VA reactivity $\left(-10.3 \pm 12.6 \mathrm{vs}-8.0 \pm 14.1\left[\Delta\left(\mathrm{mL} \cdot \min ^{-1} \cdot \mathrm{mL}^{-1} \cdot \mathrm{dL}^{-1}\right)\right] ; \mathrm{P}=0.56\right)$ 314 between acclimatization and haemodilution. Additionally, there were no differences detected in 315 relative ICA and VA reactivity to $\mathrm{CaO}_{2}\left(9.87 \pm 6.49\right.$ and $9.11 \pm 5.43\left[\Delta\left(\% \cdot \mathrm{mL}^{-1} \cdot \mathrm{dL}^{-1}\right)\right.$, 316 respectively)] following haemodilution $(\mathrm{P}=0.97)$. No regional differences between relative ICA 317 and VA reactivity to $\mathrm{CaO}_{2}$ were observed following acclimatization $(-1.80 \pm 22.14$ vs $-9.18 \pm$ $\left.31829.43\left[\Delta\left(\% \cdot \mathrm{mL}^{-1} \cdot \mathrm{dL}^{-1}\right)\right] ; \mathrm{P}=0.07\right)$ or haemodilution $\left(-1.08 \pm 29.58\right.$ vs $9.05 \pm 15.33\left[\Delta\left(\% \cdot \mathrm{mL}^{-1}\right.\right.$ $\left.319 \cdot \mathrm{dL}^{-1}\right)$ ]; $\left.\mathrm{P}=0.23\right)$. Linear regression analysis indicated there was no relationship between $\mathrm{gCBF}$ 320 reactivity and day of testing $\left(\mathrm{R}^{2}=0.209 ; \mathrm{P}=0.116\right)$. 


\section{DISCUSSION}

This study aimed to mechanistically examine the degree to which haemoconcentration at

325 high-altitude contributes to changes in CBF during acclimatization. The main findings of this 326 study were that; 1) Similar to previous studies, elevations in $\mathrm{CaO}_{2}$ through increases in $\mathrm{Hct}$, as 327 well as $\mathrm{PaO}_{2}$, occurred following approximately one-week at high-altitude, resulting in a 328 reduction in $\mathrm{CBF}$ but maintained $\mathrm{CDO}_{2}$ (Severinghaus et al., 1966; Huang et al., 1987; Jensen et 329 al., 1990; Baumgartner et al., 1994; Lucas et al., 2011; Willie et al., 2014; Subudhi et al., 2014); 330 2) Following haemodilution, an absolute reduction in Hct by $\sim 4$ resulted in a significant 331 increase in $\mathrm{gCBF}$; however, this response was blunted compared to that during acclimatization 332 where $\mathrm{CBF}$ did not return to initial arrival values. Further, changes in $\mathrm{CBF}$ following 333 haemodilution and mathematical extension of this response indicate that haemoconcentration is 334 responsible for $\sim 74 \%$ of the decrease in CBF observed during acclimatization to high-altitude. 335 This finding is further supported when the tight coupling of $\mathrm{CBF}$ to $\mathrm{CaO}_{2}$ is considered (Brown et 336 al., 1985). Indeed, CBF both during acclimatization and following haemodilution appears to be 337 tightly dictated by changes in $\mathrm{CaO}_{2}$. These findings imply that though ventilatory acclimatization 338 and elevations in haematocrit occur concomitantly during acclimatization, the 339 haemoconcentration response contributes to the $\mathrm{CBF}$ response during acclimatization to a greater 340 degree at high-altitude.

\section{Cerebral Blood Flow}

Increased $\mathrm{CBF}$ in response to a reduction in $\mathrm{CaO}_{2}$ has been observed in previous studies,

344 which demonstrates the brain's ability to maintain $\mathrm{CDO}_{2}$ during hypoxemia (Ainslie et al., 2014). 
345 This relationship is further evidenced by the reduction in CBF that occurs concomitant to 346 increased $\mathrm{CaO}_{2}$ with acclimatization to high-altitude [reviewed in: (Ainslie \& Subudhi, 2014)]. 347 Therefore, it appears that $\mathrm{CBF}$ is regulated to maintain convective oxygen delivery to the brain. 348 However, the relative contribution that haemoconcentration has on the reduction in CBF observed 349 across acclimatization had not yet been investigated.

Notably, due to the rapid diffusion of saline out of the intravascular space (Greenfield et 351 al., 1989), Hct was not fully reversed to values observed upon initial arrival to high-altitude. 352 However, as Hct has a linear inverse relationship with $\mathrm{CBF}$ through its relationship with $\mathrm{CaO}_{2}$ 353 (Brown \& Marshall, 1985; Ainslie et al., 2014), the fully reversed response can be calculated by 354 extrapolating this linear inverse relationship (Figure 2). Following mathematical correction to 355 estimate the influence of a full reversal of haemoconcentration (see "Mathematical estimation of 356 CBF with a fully normalized Hct"), gCBF did not completely return to initial arrival values 357 despite the lack of statistical difference between pre-acclimatization and the theoretical post358 haemodilution $\mathrm{CBF}$. The increase in $\mathrm{gCBF}$ following haemodilution (and mathematical extension 359 of this increase) explained $74 \%$ of the reduction in gCBF observed following acclimatization. 360 This suggests that the majority of the reduction in $\mathrm{gCBF}$ following one-week of acclimatization is 361 mediated through increases in $[\mathrm{Hb}]$ and $\mathrm{Hct}$, and their subsequent influence on $\mathrm{CaO}_{2}$. This is in 362 agreement with recent estimations made by our group (Hoiland et al., 2018). 365 changes in $\mathrm{CaO}_{2}$ and suggests that the difference in the $\mathrm{CBF}$ responses between acclimatization 366 and haemodilution are not due to alterations in hypoxic reactivity. Therefore, it stands to reason 367 that the difference between initial arrival CBF and following haemodilution (and correction for 
368 full restoration of $\mathrm{Hct}$ ) is primarily a result of ventilatory acclimatization whereby $\mathrm{SaO}_{2}, \mathrm{PaO}_{2}$, 369 and $\mathrm{pH}$ are also elevated from initial arrival at high-altitude. Indeed, $\mathrm{SaO}_{2}$ and $\mathrm{PaO}_{2}$ were 5.0\% 370 and $6.1 \mathrm{mmHg}$ higher following acclimatization, respectively, while $\mathrm{pH}$ was increased by 0.03 371 units (Table 1). Given $\mathrm{SaO}_{2}, \mathrm{PaO}_{2}$, and $\mathrm{pH}$ were unaltered during haemodilution, their influence 372 on cerebral vasomotor tone would have been unaltered and likely explains the difference between 373 initial arrival and post-haemodilution $\mathrm{CBF}$.

Differences in regional CBF have been noted at high-altitude and in hypoxia with an 375 apparent preference of flow to the posterior regions of the brain which houses the primary centers 376 for regulating physiological function upon arrival to high-altitude (Subudhi et al., 2014; 377 Feddersen et al., 2015) and during exposure to normobaric hypoxia (Willie et al., 2012). Of note, 378 we did not observe any significant regional differences between relative changes in flow 379 following acclimatization or haemodilution. Further, no differences were observed in the hypoxic 380 reactivity between the ICA and VA. This finding agrees with previous work from our group 381 conducted at the same altitude in subjects using acetazolamide (Willie et al., 2014). Differences 382 between these findings and previous research showing regional flow disparities may be related to 383 the methodology of data collection, primarily the blood flow measurement (transcranial Doppler 384 ultrasound vs duplex ultrasound) and the severity and mode of exposure to the hypoxic stimulus 385 (Hoiland et al., 2018; Willie et al., 2018) whereby a more severe step change or exposure may 386 necessitate regional blood flow prioritization to the posterior circulation as a form of survival 387 response. Further, an important consideration is that while these regional differences appear to be 388 more prevalent at highly localized levels (Binks et al., 2008; Lawley et al., 2017), bulk flow 389 measures at the VA and ICA may fail to detect these differences in some studies given that flow measures at these sites (VA \& ICA) represent the summation of multiple discrete brain regions. 
391 Further, differences in reactivity that have been noted at high-altitude are thus likely not 392 attributable to changes in Hct based on our results.

393 Following acclimatization, $\mathrm{PaO}_{2}$ and $\mathrm{SaO}_{2}$ increased through well documented 394 mechanisms of ventilatory acclimatization [reviewed in; (Hoiland et al., 2018)]. Both were 395 unaltered following haemodilution, isolating any effects of reversing ventilatory acclimatization 396 induced blood gas changes from our CBF changes attributed to acclimatization/Hct. Thus, the 397 persisting influence of $\mathrm{SaO}_{2}$ and $\mathrm{PaO}_{2}$ may represent the remaining stimulus for lower $\mathrm{CBF}$ post 398 haemodilution compared to initial arrival. Further, while $\mathrm{pH}$ was unaltered following 399 haemodilution, both pre- and post-haemodilution $\mathrm{pH}$ were higher than initial arrival. This may 400 also be driving a reduction in $\mathrm{CBF}$ and indicate our results may in fact be underestimating (albeit 401 modestly) the influence of haemoconcentration on $\mathrm{CBF}$ at altitude.

\section{Methodological considerations}

405

406 Effect of viscosity on $C B F$

Alterations in Hct occurring both chronically during acclimatization (increases) and 408 acutely during haemodilution (decreases) will lead to concomitant changes in whole blood 409 viscosity, which may subsequently affect flow through the vasculature. However, experimental 410 study has to date refuted this [(Brown \& Marshall, 1985) reviewed in (Hoiland et al., 2016)]. 411 Indeed, a reduction in blood viscosity through plasma exchange in patients with paraproteinemia, 412 whereby $\mathrm{CaO}_{2}$ and $\mathrm{PaCO}_{2}$ were constant, does not alter CBF (Brown \& Marshall, 1985). While at 
413 odds with basic physical principles (i.e., Poiseuille's Law), it is important to consider that the

414 cerebral vasculature is a complex network of compliant vessels conveying a non-newtonian fluid.

415 Thus, the conditions do not reflect those in which Poiseuille's Law was defined. Further,

416 alterations in blood viscosity can influence vascular paracrine signalling. To speculate, reductions

417 in blood viscosity would reduce the direct resistive effects of blood flow through the vessel,

418 however, the shear stress stimuli induced by viscosity would also be reduced, potentially limiting

419 dilation through reduced stimulation of shear dependent pathways (Melkumyants, Balashov, \&

420 Khayutin, 1989). This would act to increase vascular resistance. Thus, it is likely that a balance

421 exists between these two stimuli, possibly explaining why viscosity has been previously shown to

422 have a negligible effect on CBF (Brown \& Marshall, 1985). Indeed, that haemodilution leads to

423 greater increases in CBF than blood flow to other vascular beds (Crystal \& Salem, 2002; Van

424 Bommel et al., 2002) indicate the increases in CBF observed during haemodilution reflect active

425 vascular regulation.

426

427 Effect of $\mathrm{PaCO}_{2}$ and $\mathrm{pH}$

428 As expected, $\mathrm{PaCO}_{2}$ was significantly reduced following one-week of acclimatization at 429 high-altitude due to ventilatory acclimatization (Rahn \& Otis, 1949). However, we also observed 430 a $2.6 \mathrm{mmHg}$ reduction in $\mathrm{PaCO}_{2}$ following haemodilution, though both $\mathrm{PaO}_{2}$ and $\mathrm{SaO}_{2}$ were 431 unchanged. This decrease in $\mathrm{PaCO}_{2}$ in the presence of unchanged $\mathrm{PaO}_{2}$ and $\mathrm{SaO}_{2}$ has been 432 reported in a previous saline infusion study (Prisk et al., 2010) and is likely due to the dilutional 433 acidosis effect of the saline solution (Muir et al., 1975). Notably, at least at sea level, $\mathrm{PaCO}_{2}$ has 
434 been shown to effect ICA and VA flow by $\sim 6-8 \%$ per $1 \mathrm{mmHg}$ change in $\mathrm{PaCO}_{2}$ (Willie et al., 435 2012;

436 Hoiland et al., 2015). These observations indicate that, upon correction for this small alteration in

$437 \mathrm{PaCO}_{2}$, the $\mathrm{CBF}$ response would be greater following haemodilution, suggesting that the 438 contribution of $\mathrm{Hct}$ on the $\mathrm{CBF}$ response would be more substantial. However, as $\mathrm{PaCO}_{2}$ 439 primarily alters $\mathrm{CBF}$ through changes in arterial $\mathrm{pH}$ - which notably was not different pre to post 440 haemodilution - the difference in $\mathrm{PaCO}_{2}$ pre-to post-haemodilution likely had a negligible effect.

442 Blood volume expansion

443 Due to the logistical constraints and remote nature of the high-altitude expedition, a 444 hypervolemic hemodilution protocol using saline infusion was utilized as opposed to a 445 normovolemic haemodilution protocol in which blood volume would be maintained. However, 446 this may be most appropriate as the initial increases in Hct observed at altitude are due to a 447 reduced plasma volume (Siebenmann et al., 2015), thus our intervention manipulated Hct in the 448 same manner as the environmental stress of high-altitude hypoxia. Though the volume of fluid 449 utilized in this protocol was relatively large in relation to the overall blood volume of 450 participants, the crystalloid properties of the fluid infused and the time at rest between measures 451 resulted in a large portion of the infused saline leaving the vasculature (Greenfield et al., 1989). 452 This is primarily evidenced by the relatively marginal reduction in hematocrit compared to 453 volume infused and blood volume data which indicates only $540 \mathrm{~mL}$ of saline remained within 454 the vasculature at the time of CBF measurement. Further, if increases in blood volume resulted in 455 alterations in $\mathrm{CBF}$, this would be expected to coincide with alterations in cardiac parameters, (i.e. 
456 increased Q). Of note, neither of these variables were significantly elevated by hemodilution 457 suggesting there was no direct impact of volume expansion on CBF changes in this study.

458

459

460 CONCLUSIONS

461 This study was the first to experimentally investigate the degree to which CBF 462 acclimatization is driven by haemoconcentration. Through haemodilution, we were able to 463 determine that, following one-week of acclimatization, the primary mechanism contributing to the $464 \mathrm{CBF}$ response during acclimatization response is generated by diuresis and erythropoiesis465 mediated increases in $[\mathrm{Hb}]$ and $\mathrm{Hct}$, while the remaining contribution to the $\mathrm{CBF}$ response during 466 acclimatization response is likely attributable to ventilatory acclimatization.

467

468

469 References

470 Ainslie PN, Shaw AD, Smith KJ, Willie CK, Ikeda K, Graham J \& Macleod DB (2014). Stability 471 of cerebral metabolism and substrate availability in humans during hypoxia and hyperoxia. $472 \quad$ Clin Sci (Lond) 126, 661-670.

473 Ainslie PN \& Subudhi AW (2014). Cerebral blood flow at high altitude. High Alt Med Biol 15, $474 \quad 133-140$. 
475 Baumgartner RW, Bartsch P, Maggiorini M, Waber U \& Oelz O (1994). Enhanced cerebral blood 476 flow in acute mountain sickness. Aviat Sp Environ Med 65, 726-729.

477 Binks AP, Cunningham VJ, Adams L \& Banzett RB (2008). Gray matter blood flow change is 478 479 unevenly distributed during moderate isocapnic hypoxia in humans. J Appl Physiol 104, $212-217$.

480

Brown M \& Marshall J (1985). Regulation of cerebral blood flow in response to changes in blood 481 viscosity. Lancet 325, 604-609.

482 483

484 485

486

487

488

489

490

491

492

493

494

Brown MM, Wade JPH \& Marshall J (1985). Fundamental importance of arterial oxygen content in the regulation of cerebral blood flow in man. Brain 108, 81-93.

Feddersen B, Neupane P, Thanbichler F, Hadolt I, Sattelmeyer V, Pfefferkorn T, Waanders R, Noachtar S \& Ausserer H (2015). Regional differences in the cerebral blood flow velocity response to hypobaric hypoxia at high altitudes. J Cereb Blood Flow Metab 35, 1846-1851.

Gonzalez-Alonso J, Richardson RS \& Saltin B (2001). Exercising skeletal muscle blood flow in humans responds to reduction in arterial oxyhaemoglobin, but not to altered free oxygen. $J$ Physiol 530, 331-341.

Greenfield RH, Bessen HA \& Henneman PL (1989). Effect of crystalloid infusion on hematocrit and intravascular volume in healthy, nonbleeding subjects. Ann Emerg Med 18, 51-55.

Hoiland RL, Ainslie PN, Wildfong KW, Smith KJ, Bain AR, Willie CK, Foster G, Monteleone B \& Day TA (2015). Indomethacin-induced impairment of regional cerebrovascular reactivity: implications for respiratory control. J Physiol 593, 1291-1306. 
495 Hoiland RL, Bain AR, Rieger MG, Bailey DM \& Ainslie PN (2016). Hypoxemia, oxygen content, and the regulation of cerebral blood flow. Am J Physiol - Regul Integr Comp Physiol 310, R398-R413.

498

499

500

501

502

503

504

505

506

507

508

509

510

511

512

513

514

515

516

Hoiland RL, Howe CA, Coombs GB \& Ainslie PN (2018). Ventilatory and cerebrovascular regulation and integration at high-altitude. Clin Auton Res 28, 423-435.

Huang SY, Moore LG, McCullough RE, McCullough RG, Micco AJ, Fulco C, Cymerman A, Manco-Johnson M, Weil J V \& Reeves JT (1987). Internal carotid and vertebral arterial flow velocity in men at high altitude. J Appl Physiol 63, 395-400.

Jensen JB, Wright AD, Lassen NA, Harvey TC, Winterborn MH, Raichle ME \& Bradwell AR (1990). Cerebral blood flow in acute mountain sickness. J Appl Physiol JApplPhysiol 69, $430-433$.

Lang RM, Badano LP, Mor-Avi V, Afilalo J, Armstrong A, Ernande L, Flachskampf FA, Foster E, Goldstein SA, Kuznetsova T, Lancellotti P, Muraru D, Picard MH, Rietzschel ER, Rudski L, Spencer KT, Tsang W \& Voigt J-U (2015). Recommendations for Cardiac Chamber Quantification by Echocardiography in Adults: An Update from the American Society of Echocardiography and the European Association of Cardiovascular Imaging. $J$ Am Soc Echocardiogr 28, 1-39.e14.

Lawley JS, Macdonald JH, Oliver SJ \& Mullins PG (2017). Unexpected reductions in regional cerebral perfusion during prolonged hypoxia. J Physiol 595, 935-947.

Lucas SJE, Burgess KR, Thomas KN, Donnelly J, Peebles KC, Lucas RAI, Fan J-L, Cotter JD, Basnyat R \& Ainslie PN (2011). Alterations in cerebral blood flow and cerebrovascular reactivity during 14 days at $5050 \mathrm{~m}$. $J$ Physiol 589, 741-753. 
517 Muir AL, Flenley IC, Kirby BJ, Sudlow MF, Guyatt AR, Brash HM, Flenley IC \&

518 Cardiorespiratory HMB (1975). Cardiorespiratory effects of rapid saline infusion in normal man. J Appl Physiol 38, 53-59.

520 Prisk GK, Olfert IM, Arai TJ, Wagner PD \& Hopkins SR (2010). Rapid intravenous infusion of $52120 \mathrm{ml} / \mathrm{kg}$ saline does not impair resting pulmonary gas exchange in the healthy human lung.

$522 \quad J$ Appl Physiol 108, 53-59.

523 Pugh LGCE (1964). Blood volume and haemoglobin concentration at altitudes above I8,000 ft.

524 (5500 m). J Physiol 170, 344-354.

525 Rahn H \& Otis A (1949). Man's respiratory response during and after acclimatization to high $526 \quad$ altitude. Am J Physiol 157, 445-462.

527 Roach RC, Koskolou MD, Calbet JAL \& Saltin B (1999). Arterial O2 content and tension in 528 regulation of cardiac output and leg blood flow during exercise in humans. Am J Physiol $529 \quad$ Circ Physiol 276, H438-H445.

Ryan BJ, Wachsmuth NB, Schmidt WF, Byrnes WC, Julian CG, Lovering AT, Subudhi AW \&

531 Roach RC (2014). AltitudeOmics: rapid hemoglobin mass alterations with early 532 acclimatization to and de-acclimatization from $5260 \mathrm{~m}$ in healthy humans. PLoS One 9, $533 \quad$ e108788.

534 Schmidt W \& Prommer N (2005). The optimised CO-rebreathing method: a new tool to 535 determine total haemoglobin mass routinely. Eur J Appl Physiol 95, 486-495.

536 Severinghaus JW, Chiodi H, Ii EIE, Brandstater B \& Hornbein TF (1966). Cerebral Blood Flow 
In Man at High Altitude. 19, 274-282.

538

539

540

541

542

543

544

545

546

547

548

549

550

551

552

553

554

555

556

557

Siebenmann C, Robach P \& Lundby C (2017). Regulation of blood volume in lowlanders exposed to high altitude. J Appl Physiol 123, 957-966.

Stembridge M, Ainslie PN, Hughes MG, Stöhr EJ, Cotter JD, Nio AQX \& Shave R (2014).

Ventricular structure, function, and mechanics at high altitude: chronic remodeling in Sherpa vs. short-term lowlander adaptation. J Appl Physiol 117, 334-343.

Subudhi AW, Fan J-L, Evero O, Bourdillon N, Kayser B, Julian CG, Lovering AT \& Roach RC (2014). AltitudeOmics: effect of ascent and acclimatization to $5260 \mathrm{~m}$ on regional cerebral oxygen delivery. Exp Physiol 99, 772-781.

Willie CK, Macleod DB, Shaw AD, Smith KJ, Tzeng YC, Eves ND, Ikeda K, Graham J, Lewis NC, Day TA \& Ainslie PN (2012). Regional brain blood flow in man during acute changes in arterial blood gases. J Physiol 590, 3261-3275.

Willie CK, MacLeod DB, Smith KJ, Lewis NC, Foster GE, Ikeda K, Hoiland RL \& Ainslie PN (2015). The contribution of arterial blood gases in cerebral blood flow regulation and fuel utilization in man at high altitude. J Cereb Blood Flow Metab 35, 873-881.

Willie CK, Smith KJ, Day T a, Ray L a, Lewis NCS, Bakker a, Macleod DB \& Ainslie PN (2014). Regional cerebral blood flow in humans at high altitude: gradual ascent and 2 wk at 5,050 m. J Appl Physiol 116, 905-910.

Willie CK, Stembridge M, Hoiland RL, Tymko MM, Tremblay JC, Patrician A, Steinback C, Moore J, Anholm J, Subedi P, Niroula S, McNeil CJ, McManus A, MacLeod DB \& Ainslie PN (2018). UBC-Nepal Expedition: An experimental overview of the 2016 University of 
British Columbia Scientific Expedition to Nepal Himalaya ed. Torrens C. PLoS One 13, e0204660.

\section{ACKNOWLEDGEMENTS}

This study was conducted within the framework of the Ev-K2-CNR Italian Pyramid Research Laboratory. The authors are grateful to the other members of the 2016 UBC International

Research Expedition to Mt. Everest for invaluable help with logistical planning and implementation of this research study.

\section{AUTHOR CONTRIBUTIONS}

C.A.H., P.N.A., \& R.L.H. conceived the study design. C.A.H., P.N.A., J.C.T., H.H.C., A.P., M.S., A.W., E.D., M.G.R., M.T., C.G., A.S., D.B.M., \& R.L.H. were involved in data collection. C.A.H., P.N.A., J.C.T., M.S., A.L.D., \& R.L.H. were involved in data analyses and interpretation. C.A.H., P.N.A., \& R.L.H. drafted the manuscript. All authors critically reviewed and approved the final version of this manuscript.

\section{FUNDING}

75 R.L.H was supported by a Natural Sciences and Engineering Research Council of Canada

Postgraduate Scholarship. P.N.A, was supported by a Canada Research Chair, NSERC Discovery

77 Grant and the Canadian Foundation of Innovation. J.C.T was supported by a Natural Sciences and

Engineering Research Council of Canada Alexander Graham Bell Canada Graduate Scholarship 
579 and Queen's University Graduate Dean's Travel Grant for Doctoral Field Research. M.M.T was

580 supported by a Natural Sciences and Engineering Research Council of Canada Alexander

581 Graham Bell Canada Graduate Scholarship.

582

583 CONFLICT OF INTEREST

584 The authors declare no conflicts of interest, financial or otherwise.

585

586

587

588

589

590

591

592 TABLES

593

594 Table 1. Arterial blood gases at high altitude.

\begin{tabular}{llll}
\hline & Arrival at 5050m & Pre-Haemodilution & Post-Haemodilution \\
\hline $\mathrm{CaO}_{2}(\mathrm{~mL} \cdot \mathrm{dL})$ & $15.4 \pm 1.6$ & $18.6 \pm 1.3^{*}$ & $17.2 \pm 1.0^{* \dagger}$ \\
$\mathrm{Hct}(\%)$ & $42.5 \pm 2.5$ & $49.6 \pm 2.5^{*}$ & $45.6 \pm 2.3^{* \dagger}$ \\
{$[\mathrm{Hb}](\mathrm{g} \cdot \mathrm{dL})$} & $14.3 \pm 0.8$ & $16.2 \pm 0.8^{*}$ & $14.9 \pm 0.8^{*} \dagger$
\end{tabular}




$\begin{array}{llll}\mathrm{PaCO}_{2}(\mathrm{mmHg}) & 29.6 \pm 1.8 & 23.6 \pm 2.1^{*} & 21.0 \pm 1.5^{* \dagger} \\ \mathrm{pH} & 7.47 \pm 0.02 & 7.50 \pm 0.02^{*} & 7.49 \pm 0.02^{*} \\ \mathrm{PaO}_{2}(\mathrm{mmHg}) & 40.6 \pm 4.7 & 46.7 \pm 4.2^{*} & 47.0 \pm 3.4^{*} \\ \mathrm{SaO}_{2}(\%) & 78.3 \pm 5.6 & 83.3 \pm 4.1^{*} & 83.7 \pm 3.5^{*}\end{array}$

$595 *$ significant difference from arrival at 5050m

$596 \uparrow$ significant difference between pre- and post-haemodilution 
597 Table 2. Cardiovascular parameters upon arrival to high-altitude and pre- and post598 haemodilution

\begin{tabular}{llll}
\hline & Arrival at 5050m & Pre-Haemodilution & Post-Haemodilution \\
\hline MAP $(\mathrm{mmHg})$ & $99 \pm 12$ & $108 \pm 10^{*}$ & $111 \pm 9 *$ \\
HR $(\mathrm{bpm})$ & $65 \pm 18$ & $58 \pm 11$ & $53 \pm 12^{*}$ \\
$\mathrm{SV}(\mathrm{mL})$ & $69 \pm 13$ & $54 \pm 11^{*}$ & $63 \pm 8.8 \dagger$ \\
Q $\left(\mathrm{L} \cdot \mathrm{min}^{-1}\right)$ & $4.45 \pm 1.52$ & $3.09 \pm 0.65^{*}$ & $3.28 \pm 0.65$
\end{tabular}

$599 *$ significant difference from arrival at 5050m

$600 \uparrow$ significant difference between pre- and post-haemodilution 
601 Table 3. Individual blood volume data pre- and post-haemodilution

\begin{tabular}{|c|c|c|c|c|c|c|c|c|}
\hline \multicolumn{5}{|c|}{ Pre-Haemodilution } & \multicolumn{4}{|c|}{ Post-Haemodilution } \\
\hline Subject & $\begin{array}{l}\text { Hct } \\
(\%)\end{array}$ & $\begin{array}{l}\text { Hct } \\
\text { Volume (L) }\end{array}$ & $\begin{array}{l}\text { Plasma } \\
\text { Volume (L) }\end{array}$ & $\begin{array}{l}\text { Blood } \\
\text { Volume (L) }\end{array}$ & $\begin{array}{l}\text { Hct } \\
(\%)\end{array}$ & $\begin{array}{l}\text { Hct } \\
\text { Volume (L) }\end{array}$ & $\begin{array}{l}\text { Plasma } \\
\text { Volume (L) }\end{array}$ & $\begin{array}{l}\text { Blood } \\
\text { Volume (L) }\end{array}$ \\
\hline 1 & 47.4 & 2.661 & 2.953 & 5.613 & 43.4 & 2.661 & 3.470 & 6.131 \\
\hline 2 & 53.2 & 2.911 & 2.561 & 5.472 & 48.9 & 2.911 & 2.989 & 5.900 \\
\hline 3 & 50.2 & 2.569 & 2.549 & 5.118 & 46.6 & 2.569 & 2.923 & 5.492 \\
\hline 4 & 50.8 & 3.555 & 3.443 & 6.997 & 46.1 & 3.555 & 4.110 & 7.665 \\
\hline 5 & 49 & 3.799 & 3.954 & 7.753 & 45.4 & 3.799 & 4.550 & 8.349 \\
\hline 6 & 49 & 2.787 & 2.900 & 5.687 & 45.5 & 2.787 & 3.325 & 6.111 \\
\hline 7 & 49.8 & 2.927 & 2.951 & 5.878 & 45.2 & 2.927 & 3.522 & 6.449 \\
\hline 8 & 50.6 & 3.607 & 3.521 & 7.128 & 45.4 & 3.607 & 4.288 & 7.895 \\
\hline 9 & 50.8 & 3.474 & 3.365 & 6.839 & 45.6 & 3.474 & 4.094 & 7.569 \\
\hline 10 & 50.1 & 2.896 & 2.884 & 5.780 & 46.8 & 2.896 & 3.271 & 6.167 \\
\hline 11 & 52.9 & 3.695 & 3.290 & 6.985 & 49.3 & 3.695 & 3.747 & 7.442 \\
\hline 12 & 43.3 & 2.411 & 3.157 & 5.568 & 40.5 & 2.411 & 3.572 & 5.983 \\
\hline 13 & 47 & 2.604 & 2.936 & 5.540 & 43.6 & 2.604 & 3.619 & 6.223 \\
\hline MEAN & 49.5 & 3.069 & 3.113 & 6.181 & 45.6 & 3.069 & 3.652 & 6.721 \\
\hline SD & 2.6 & 0.486 & 0.396 & 0.834 & 2.3 & 0.486 & 0.492 & 0.924 \\
\hline
\end{tabular}

602 Individual blood volume data pre- and post-haemodilution. Plasma volume and total blood 603 volume are derived from the Hct \% and total Hct volume measured using a CO re-breath test 604 performed one-day prior to the haemodilution protocol. 
605 FIGURES

606

607

608

609

610

611

612

613

614

615

616

617

618

619

620

621

622

623

624

625

626

627

628

629

630

631

632

633

634
Figure 1. Experimental overview of the study protocol. Participants ascended to $5050 \mathrm{~m}$ over a 9-day period involving rapid ascent by plane to $2860 \mathrm{~m}$, and ambulatory ascent onward to 5050 m. Cerebral blood flow (CBF), arterial blood gases (ABGs), blood pressure (BP), cardiac output (Q) and heart rate (HR) were recorded at all three time points.

Figure 2. Cerebral blood flow during acclimatization and following haemodilution. At the arrival time point, sample sizes were reduced for the internal carotid artery (ICA; $n=11$ ), vertebral artery (VA; $n=11)$, and global cerebral blood flow (gCBF; $n=10)$. Data was successfully collected in all participants $(\mathrm{n}=13)$ following one-week of acclimatization at $5050 \mathrm{~m}$ (pre-hemo) and following hypervolemic haemodilution (post-hemo). "Estimated" data (denoted by the grey background) are based on theoretical calculations for a fully normalized Hct (see "Theoretical calculation of CBF with a fully normalized Hct"). Blood flow was calculated to assume a complete reversal of haematocrit to initial arrival values (i.e. greater extent of haemodilution). Open circles represent individual data points with dotted lines tracking within subject changes. Black horizontal lines represent the average flow at each time point. ${ }^{*}$ signifies a significant difference from arrival at 5050m. $\uparrow$ signifies a significant difference pre- to post- haemodilution. Significance is set a $\mathrm{P}<0.05$

Figure 3. Cerebrovascular reactivity to acclimatization and haemodilution. Reactivity to changes in $\mathrm{CaO}_{2}$ was not different across acclimatization (Initial arrival to pre-hemo) compared to during haemodilution (pre-hemo to post-hemo). gCBF, global cerebral blood flow; ICA, internal carotid artery; VA, vertebral artery. No differences in reactivity were observed between the ICA and VA at any time point. Data are presented as mean \pm SD. 


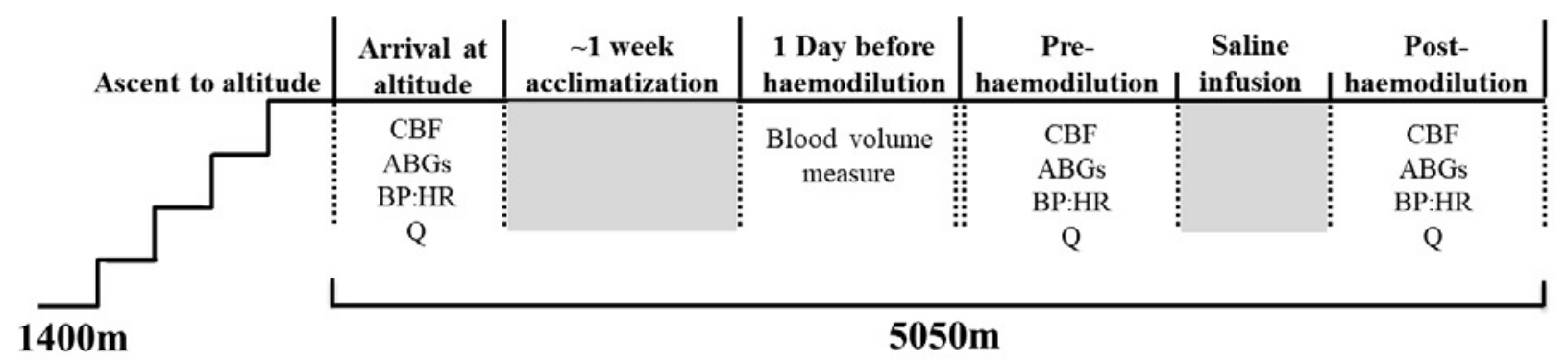



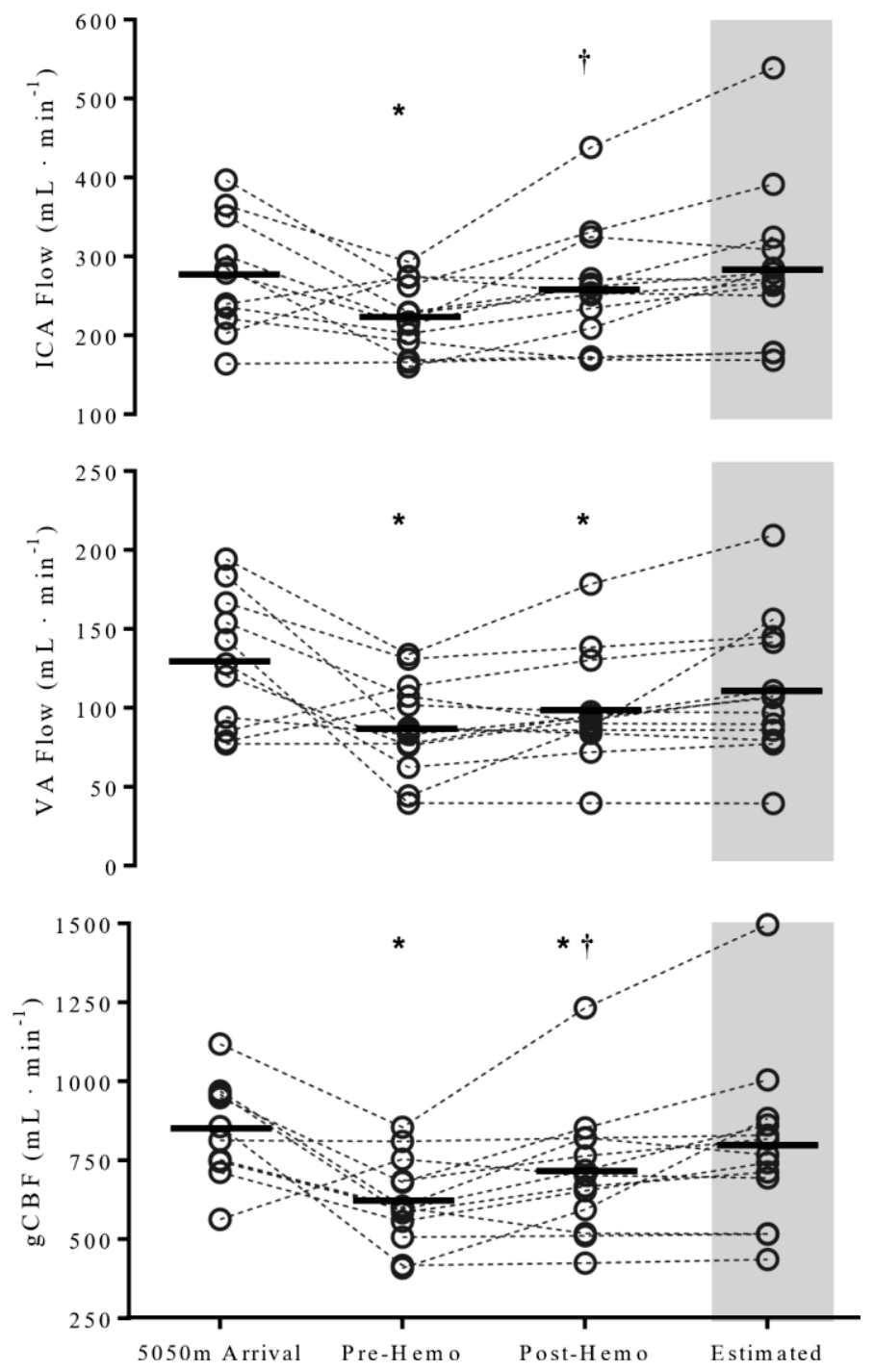


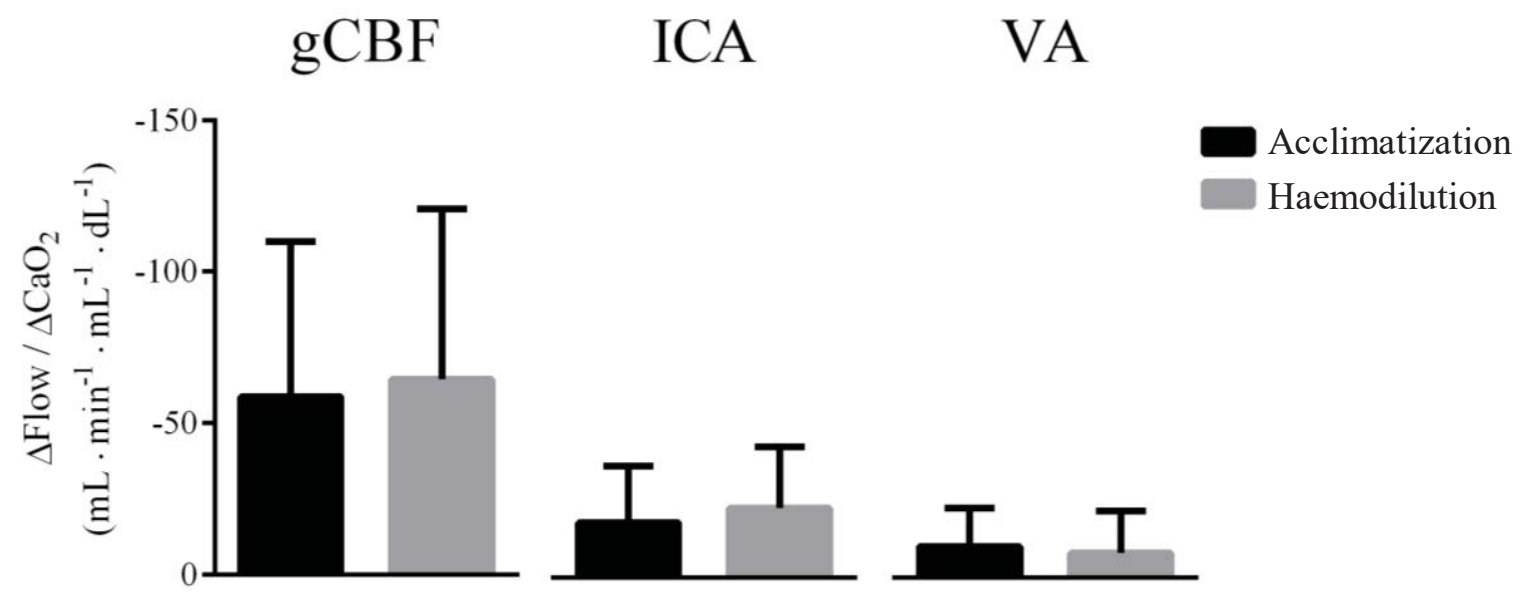

